\title{
A educação no âmbito dos debates sobre o currículo escolar e valorização da vida
}

Education in the framework of debates about the school curriculum and valuing life

La educación en el marco de los debates sobre el currículo escolar y la valoración de la vida

Anecléia Rodrigues de Lima

ORCID: https://orcid.org/0000-0002-2399-5106 Universidade Estadual da Paraíba, Brasil E-mail:anecleialima@gmail.com

Cynara Maria Dantas Vieira Leite ORCID: https://orcid.org/0000-0002-4280-3755 Universidade Estadual da Paraíba, Brasil E-mail:cynaramariadantas@gmail.com

Alexandre Silva de Lima ORCID: https://orcid.org/0000-0002-5199-5664 Universidade Federal de Campina Grande, Brasil

E-mail:economia.alexandresilva@gmail.com

Igo Marinho Serafim Borges ORCID: https://orcid.org/0000-0002-3662-1859 Universidade Federal de Campina Grande, Brasil

E-mail: igomarinho27@gmail.com

Amanda Cristiane Gonçalves Fernandes

ORCID: https://orcid.org/0000-0001-8462-6171

Universidade Federal de Campina Grande, Brasil

E-mail: amandafernandestt@gmail.com

Jean Oliveira Campos

ORCID: https://orcid.org/0000-0002-2874-754X Universidade Federal da Paraíba, Brasil

E-mail: jeannolliveira@gmail.com

Emanuelly Cristovão Barbosa da Silva

ORCID: https://orcid.org/0000-0003-3835-1132

Universidade Estadual da Paraíba, Brasil

E-mail: cristovamemanuelly@gmail.com

Miriam Souza Martins

ORCID: https://orcid.org/0000-0002-3512-4770

Universidade Federal de Campina Grande, Brasil

E-mail:miriam2009souza@gmail.com

Jucianny Araújo da Silva

ORCID: https://orcid.org/0000-0001-8199-9212

Universidade Estadual da Paraíba, Brasil

E-mail: juciannyaraujo@gmail.com

João Guilherme Tejo Barros Freire

ORCID: https://orcid.org/0000-0002-4496-3250

Universidade Estadual da Paraíba, Brasil

E-mail: contatojoaofreire2@gmail.com

Érica Dantas de Oliveira Batista

ORCID: https://orcid.org/0000-0002-9688-5434

Universidade Estadual da Paraíba, Brasil

E-mail: ericadantasbatista@gmail.com

Cicero Ricardo Barbosa de Paiva

ORCID: https://orcid.org/0000-0002-1554-9552

Universidade Estadual Vale do Acaraú, Brasil

E-mail: prof.ricardopaivace@gmail.com

Paulo de Souza Albuquerque Junior ORCID: https://orcid.org/0000-0003-0704-7998

Universidade Estadual da Paraíba, Brasil

E-mail: paulojuniorh13@gmail.com

Magna Jussara Rodrigues Santos

ORCID: https://orcid.org/0000-0001-8026-6607

Universidade Estadual da Paraíba, Brasil

E-mail:magna.santos@aluno.urpb.edu.br 


\begin{abstract}
Resumo
A instituição escolar é um espaço privilegiado de construção de cidadania, portanto deve e pode constituir-se em espaço efetivo de exercício de convívio democrático e solidário, aspectos que constituirão o conteúdo da própria educação em valores. O objetivo deste trabalho é observar a educação em valores no âmbito dos debates sobre o currículo escolar e valorização da vida. Utilizando uma metodologia descritiva, visto que foi feito revisão bibliográfica, para adquirir conhecimentos, selecionar as obras que nortearam a discursão em torno do objetivo do estudo e com isso foram discutidos temas como: a educação em valores e currículo escolar. Citando autores como: Ponce (2009), Moreira (2007), Gomes (2007), Vandal et al, (2015), Salvino et al, (2018) entre outros. Com o atual senário da educação brasileira nos leva refletir vários pontos de suma importância, que realmente interferem no desenvolvimento do profissional, assim como no desenvolvimento educacional das crianças. Por meio de sua análise, o artigo considerou alguns dos desafios iniciais relacionados a recursos humanos e materiais inadequados, incongruências entre conteúdo e práticas pedagógicas e pouca participação do público. De acordo com todas as pesquisas realizadas para elaboração do trabalho, conclui-se que a educação brasileira necessita de mudanças, mudanças essas que se volte mais para a realidade da escola.
\end{abstract}

Palavras-chave: Currículo; Valores; Educação.

\begin{abstract}
The school institution is a privileged space for the construction of citizenship, therefore it must and can become an effective space for the exercise of democratic and solidary coexistence, aspects that will constitute the content of education itself in values. The objective of this work is to observe the education in values in the scope of the debates about the school curriculum and the valorization of life. Using a descriptive methodology, since a bibliographic review was carried out, to acquire knowledge, select the works that guided the discussion around the objective of the study and with that, topics such as: education in values and school curriculum were discussed. Citing authors such as: Ponce (2009), Moreira (2007), Gomes (2007), Vandal et al, (2015), Salvino et al, (2018) among others. With the current scenario of Brazilian education, it leads us to reflect on several extremely important points, which really interfere in the development of the professional, as well as in the educational development of children. Through its analysis, the article considered some of the initial challenges related to inadequate human and material resources, inconsistencies between content and pedagogical practices, and poor public participation. According to all the research carried out for the elaboration of the work, it is concluded that Brazilian education needs changes, changes that are more focused on the reality of the school.
\end{abstract}

Keywords: Curriculum; Values; Education.

\title{
Resumen
}

La institución escolar es un espacio privilegiado para la construcción de ciudadanía, por lo que debe y puede convertirse en un espacio efectivo para el ejercicio de la convivencia democrática y solidaria, aspectos que constituirán el contenido mismo de la educación en valores. El objetivo de este trabajo es observar la educación en valores en el ámbito de los debates sobre el currículo escolar y la valorización de la vida. Utilizando una metodología descriptiva, ya que se realizó una revisión bibliográfica, para adquirir conocimientos, seleccionar los trabajos que orientaron la discusión en torno al objetivo del estudio y con ello se discutieron temas como: la educación en valores y el currículo escolar. Citando autores como: Ponce (2009), Moreira (2007), Gomes (2007), Vandal et al, (2015), Salvino et al, (2018) entre otros. Con el escenario actual de la educación brasileña, nos lleva a reflexionar sobre varios puntos de suma importancia, que realmente interfieren en el desarrollo del profesional, así como en el desarrollo educativo de los niños. A través de su análisis, el artículo consideró algunos de los desafíos iniciales relacionados con los recursos humanos y materiales inadecuados, las inconsistencias entre el contenido y las prácticas pedagógicas, y la escasa participación pública. De acuerdo con toda la investigación realizada para la elaboración del trabajo, se concluye que la educación brasileña necesita cambios, cambios que estén más centrados en la realidad de la escuela.

Palabras clave: Currículo; Valores; Educación.

\section{Introdução}

A mudança do tradicionalismo para uma abordagem construtivista da reforma educacional é um fator de justiça social. Embora centralize questões de identidade, cultura, poder e posição social, perde o foco e torna-se fraco na questão do conhecimento. Ao mesmo tempo em que prevê competências e habilidades genéricas e a inclusão de vozes dos subalternos, ela mina a base do conhecimento valioso ao qual os alunos precisam ser expostos (Sacuda, 2018). As limitações do construtivismo estão, portanto, ligadas à sua incapacidade de oferecer aos alunos da classe trabalhadora uma experiência de aprendizagem transformadora que transcenda seu meio imediato, o que acaba consolidando e perpetuando as desigualdades sociais (Galian et al., 2021). 
Portanto, é compreensível que as questões definidas nos objetivos da reforma ao longo dos anos tenham variado desde o desenvolvimento de habilidades para lidar com uma grande população de jovens desempregados, a relevância da educação para atender e atender suas necessidades de socialização e vocacional para um estado desenvolvimentista, expansão do ensino superior através da criação das universidade e faculdades, desenvolvendo jovens felizes que abraçam os valores nacionais e estão prontos para servir seu país (Pais, 2016). É necessário portanto, que os investimentos em educação de qualidade chegue para todos os cidadão, sem exclusão por cor, gênero, idade ou classe social (Yannoulas et al., 2012).

Desta forma, buscar a educação em valores, superando a prescrição moralista, situando-a no nível da ética, é preocupação recente na história da educação escolar e merece o nosso olhar cuidadoso (Ponce, 2009). Portanto, o currículo deve ser visto, analisado e pensado em especial para todo o público de alunos nas suas diferentes condições sociais e econômicas, visto que o direito a educação de qualidade é para todos e deve ser pensado de forma cuidadosa (Ropoli et al., 2010). A partir do tema proposto, foi possível discutir e refletir sobre a educação em valores no âmbito dos debates sobre o currículo escolar e a valorização da vida (Romeiro, 2011).

O objetivo deste trabalho é observar a temática da educação em valores no âmbito dos debates sobre o currículo escolar e valorização da vida. Seja pelo desgaste do tema, pela presença de novas tendências na teoria e na prática curriculares, pelo desenvolvimento tecnológico as redes sociais, seja pela valorização maior no processo educativo do seu caráter instrucional, ou ainda, por uma interpretação redutora do tema; o problema é que podemos perceber que a educação tem sido negligenciada, diluída ou reduzida, e até mesmo causado problemas escolares e familiares que levam a sérios complicações de saúde com alunos como também com professores.

Desta forma, há uma preocupação em se pensar e repensar o trabalho desenvolvido nas escolas e nas universidades, tendo o currículo como norte fundamental a esta proposta, visando um trabalho que promova um ensino que vá ao encontro do respeito e valorização da vida.

\section{Metodologia}

Trata-se de um trabalho de revisão bibliográfica narrativa, que serão discutidos temas como: a educação em valores observando que a educação do sujeito moral demanda uma ação socialmente complexa quando fundada na liberdade de pensamento e na responsabilidade; currículo escolar- abordando o fato das escolas trabalharem com propostas centralizadas de currículo, com aulas prontas, apostiladas, sequenciadas, fechadas em tempos determinados, que não preveem a presença dos sujeitos envolvidos na prática educativa, a não ser como executores estritos da prescrição pedagógica (Nascimento, 2015).

Desta forma, a revisão bibliográfica narrativa são publicações amplas, que permitem discutir e descrever o desenvolvimento de um determinado assunto, ou de um determinado estudo, sob ponto de vista teórico e/ou contextual (Casarin, 2020). As revisões narrativas não informam as fontes de informação utilizadas, a metodologia para busca das referências, nem os critérios utilizados na avaliação e seleção dos trabalhos Constituem, basicamente, de análise da literatura publicada como é o caso de livros, artigos de revista impressas e/ou eletrônicas na interpretação e análise crítica pessoal do autor que está utilizando da metodologia em questão (Santos et al., 2021).

Essa metodologia têm um papel fundamental para a educação continuada pois, permitem ao leitor adquirir e atualizar o conhecimento sobre uma temática específica em curto espaço de tempo; porém não possuem metodologia que permitam a reprodução dos dados e nem fornecem respostas quantitativas para questões específicas (Hayashi, \& Gonçalves, 2018).

No levantamento bibliográfico e documental, a primeira preocupação foi adquirir através do google acadêmico artigos que trouxessem uma literatura pertinente a discussão em questão, utilizou-se palavras chaves como educação escolar, currículo e escola, valoração da vida na escola, escola e família. Após essa pesquisa selecionamos apenas os artigos que melhor se 
encaixavam com a nossa proposta a ser discutida. Em seguida, após ter selecionado todos o s materiais que serviram como referencial teórico e base para nossa discussão foi possível ter conhecimentos de diversas obras que norteavam a discursão em torno do objetivo do estudo. Em seguida foi feito uma leitura sistemática de cada documento, o que foi fundamental para elaboração do trabalho.

\section{Resultados e Discussão}

\subsection{A escola e o currículo}

A instituição escolar é um espaço privilegiado de construção de cidadania, portanto deve e pode constituir-se em espaço efetivo de exercício de convívio democrático e solidário, aspectos que constituirão o conteúdo da própria educação em valores (Alves et al., 2020).

A escola, por sua vez, é uma instituição, que organiza-se para garantir a aprendizagem de todos, comprometendo-se com ela e preservando-a, construindo um novo vínculo pedagógico, resgatando o sentido do estudo, mediante uma proposta pedagógica significativa e participativa, é o espaço onde a criança, ao pisar pela primeira vez, toma consciência social da sua diferença (Luck, 2017).

O trabalho realizado na escola, visa promover a educação, é pautado no desenvolvimento do currículo, sendo este, um documento constituído a partir de orientações básicas para o trabalho do professor, visando promover a educação, a partir de aprendizagens propiciadas aos alunos de forma que estes possam atuar na sociedade de maneira digna e crítica (Ponce, 2009).

O currículo é organizado por competências, com base comum de conhecimentos. Ou seja, é composto por competências de diversas áreas (natureza, humanas, linguagens e códigos, exatas) que visam garantir aos alunos um desenvolvimento intelectual e social que os possibilite preparo à vida, apropriando-se dos saberes adquiridos na escola (Moreira, 2007).

Assim como o currículo de base comum também existe outro material que traz orientações para o trabalho do professor são os Parâmetros Curriculares Nacionais - PCNs, que são documentos de base nacional.

Os Parâmetros Curriculares Nacionais constituem um referencial de qualidade para a educação no Ensino Fundamental em todo o País. Sua função é orientar e garantir a coerência dos investimentos no sistema educacional, socializando discussões, pesquisas e recomendações, subsidiando a participação de técnicos e professores brasileiros, principalmente daqueles que se encontram mais isolados, com menor contato com a produção pedagógica atual. (Brasil, 1997).

Os Parâmetros curriculares nacionais são organizados por área de conhecimento que visam o desenvolvimento de conceitos e valores a fim de promover a democracia e cidadania (Gomes, 2007).

Assim como os PCNs, existe a LDB e outros documentos como Diretrizes Curriculares Nacionais para a Educação Básica e a Base Nacional Comum Curricular, que buscam qualificar e organizar a educação básica do país. São documentos que apresentam normas obrigatórias que orientam o planejamento curricular das escolas e dos sistemas de ensino (Alves et al., 2020).

As Diretrizes Curriculares Nacionais para Educação Básica, são um conjunto de definições doutrinadas sobre princípios, fundamentos e procedimentos na educação básica que orientam as escolas na organização, articulação, desenvolvimento e avaliação de suas propostas pedagógicas (Ponce, 2009).

Enquanto isso, a Base Nacional Comum Curricular (BNCC), é um documento de caráter normativo que define o conjunto orgânico e progressivo de aprendizagens essenciais que todos os alunos devem desenvolver ao longo das etapas e modalidades da educação básica. Conforme definido na Lei de Diretrizes e Bases da Educação Nacional (LDB, Lei n9.394/1996), a base deve nortear os currículos dos sistemas e redes de ensino das Unidades Federais, como também as propostas pedagógicas de todas as escolas públicas e privadas de Educação Infantil, Ensino Fundamental e Ensino Médio, em todo o Brasil (Brasil, 1997). 
A Base estabelece conhecimentos, competências e habilidades que se espera que todos os estudantes desenvolvam ao longo da escolaridade básica. Orientada pelos princípios éticos, políticos e estéticos traçados pelas Diretrizes Curriculares Nacionais da Educação Básica, a Base soma-se aos propósitos que direcionam a educação brasileira para a formação humana integral e para a construção de uma sociedade justa, democrática e inclusiva (Brasil, 1997).

A função de todos esses documentos é orientar a escola, assim como o professor a planejar e elaborar o Plano Político Pedagógico da instituição. Procurando desenvolver um currículo pelo qual seja didático, facilitando assim o aprendizado e o desenvolvimento intelectual do aluno, tratando o currículo como algo que seja flexível, relacionando às disciplinas, por meio da interdisciplinaridade, que possam formar alunos preparados para atuar na sociedade, compreendendo o mundo em que vivemos, respeitando e valorizando o próximo (Oliveira, 2015).

Mas infelizmente sabemos que nem sempre funciona dessa forma e muitos problemas são acarretados tanto ao professor como a do alunado. Formando alunos frustrados, desencadeando problemas como depressão, ansiedade e o uso excessivo de medicamentos, de modo que a saúde fragilizada dos estudantes se conecta com as causas de suicídios no meio acadêmico em todo o Brasil.

\subsection{A educação em valores}

O conhecimento do aluno, o desenvolvimento de sua capacidade, o uso de suas habilidades dependem de um ambiente que favoreça a aprendizagem e do desempenho do professor, que deverá proporcionar um "conjunto de ferramentas" culturais, a fim de favorecer o progresso mental (Van Dal et al., 2015).

A educação do sujeito moral demanda uma ação socialmente complexa quando fundada na liberdade de pensamento e na responsabilidade. Não se trata apenas de ditar as regras e fazer cumpri-las, trata-se de preservar o espaço para que a regra seja repensada, acolhida ou rejeitada, mas sempre objeto de reflexão, cujo princípio é o respeito ao outro (Goergen, 2005).

A educação ganha maior importância quando direcionada ao pleno desenvolvimento humano e às suas potencialidades e a elevação da autoestima dos grupos socialmente excluídos, de modo a efetivar a cidadania plena para a construção de conhecimentos, no desenvolvimento de valores, crenças e atitudes em favor dos direitos humanos, na defesa do meio ambiente, dos outros seres vivos e da justiça social (Fernandes et al., 2010).

Segundo Freire (1975) enrijecer regras, engessar comportamentos, disciplinar, não é construir indivíduos éticos. Há que instrumentalizá-los com o aprendizado de um pensar crítico, reflexivo e responsável. De acordo com o mesmo autor, educar em valores é educar para a liberdade.

E um dos grandes vilões da educação é o currículo, pelo fato de privilegiar a cognição e preocupando-se em avaliar conteúdos, estritamente compreendidos. As instituições educacionais, sejam elas federais, estaduais, municipais ou privadas de ensino têm trabalhado com propostas centralizadas de currículo, com aulas prontas, apostiladas, sequenciadas, fechadas em tempos determinados, que não preveem a presença dos sujeitos envolvidos na prática educativa, e sim como executores estritos da prescrição pedagógica.

A escola é um ambiente onde os conteúdos são mais importantes do que os valores e que os mesmos estão apenas implícitos em atitudes, tanto do professor como na escola de modo geral. E com isso há um conflito entre o que é ser professor e a relação deste com a construção de valores, pois um professor que apenas está interessado em passar conteúdo não deveria estar, necessariamente, preocupado com a formação de valores de seus alunos.

O atual senário da educação brasileira nos leva refletir vários pontos de suma importância, que realmente interferem no desenvolvimento do profissional, assim como no desenvolvimento educacional das crianças e dos adolescentes. E a vocação para ser um bom professor, é um dos pontos que se deve observar, já que boa parte dos profissionais exercem a função apenas por 
necessidades financeiras e não por vocação.

E isso acaba levando a inúmeros outros problemas, tanto para o profissional quanto para os alunos que ali estão diante de um professor estressado, sem estimulo, e sem o real olhar do educador para educar de forma correta seu aluno. E com isso não indo de acordo com a LDB- Lei de Diretrizes e Bases da Educação Nacional, no Art. 13 inciso III, que os docentes incumbirse-ão de zelar pela aprendizagem dos alunos (Borçari et al., 2014).

E o que realmente precisa, é mudar a forma como as coisas são organizadas, falta acordo múltiplo, uma gestão organizada para as coisas fluírem com mais êxito. Produzir direções, caminhos e modelos diferentes de acordo com a necessidade de cada realidade, para assim buscar bons resultados e parar de se apegar a mitos.

Não adianta construir prédios, fazer formação de professores, porque a realidade da educação é outra, o grande desafio está no projeto pedagógico. O que precisa é estruturar, lincar e os fazer encaixes e conexões. Precisa-se trabalhar com a realidade existente em cada escola, em cada aluno, valorizando o saber do aluno, para assim buscar bons resultados. E não levar o aluno a problemas psicológicos, estresses, ansiedades, perdendo o interesse pelos estudos e muitos até pela vida chegando a cometer o suicídio (Pereira, 2014).

Assim conectando as boas práticas e fortalecendo as conexões em rede, já que a sociedade do mundo de hoje vive na era digital, aproveitar essa ferramenta de maneira correta para assim ensinar os alunos a aprender e a criar conhecimento, trabalhando dentro de uma lógica de rede, conectando os saberes de forma multidisciplinar (Bacich et al., 2015). E assim produzir direções, caminhos e modelos diferentes de acordo com a necessidade de cada realidade.

De acordo com Salvino et al., (2018), a inovação se apresenta como demanda que mobiliza diferentes identidades (estudantes, professores, pais, gestores, partidos, sindicatos e outros) para suplementar tal falta. Contudo, a inovação não tem um conteúdo objetivo e os grupos (identidades) passam a vislumbrá-la por diferentes meios e reivindicações.

\section{Conclusão}

A partir de tais discussões, concluiu-se que a educação brasileira precisa de mudança, de seguir um modelo que volte mais para realidade da escola, para o aprendizado do aluno, mas, que não saia da grade curricular, que siga os parâmetros curriculares, as diretrizes curriculares nacionais, a LDB, mas que o currículo possa ser de fato articulado a questão da diversidade, abordando os temas de maneira eficaz, para que a formação dos alunos garanta uma sociedade que caminhe rumo à cidadania, onde todos sejam respeitados, cada um com sua diferença.

Desta forma, se faz necessário que os alunos insiram-se como partes interessadas incluindo-os nos debates sobre a mudança curricular. Isso dará aos inovadores capital social e uma oportunidade de se engajar significativamente com suas posições para apoiar ou resistir à inovação. Uma maior participação pública na busca de maior legitimidade, sensibilização e educação cívica poderia ter ajudado a consolidar os objetivos do novo currículo na sociedade em geral.

Como sugestão de trabalhos futuros podem ser desenvolvida pesquisas referente a importância da BNCC para a uniformização do ensino nas escolas públicas e privadas do Brasil, outra sugestão é a importância da BNCC para os anos iniciais e finais do ensino fundamental.

\section{Referências}

Alves, S. M. C., \& Barbosa, M. R. B. (2020). Gestão escolar democrática: dimensão diretiva aos processos educacionais significativos. Research, Society and Development, 9(4), e139942985-e139942985.

Bacich, L., Neto, A. T., \& de Mello Trevisani, F. (2015). Ensino híbrido: personalização e tecnologia na educação. Penso Editora.

BRASIL, Ministério da Educação, (1997). Parâmetros curriculares nacionais: apresentação dos temas transversais, ética. Brasília, MEC/SEF. 
BRASIL. Secretaria de Educação Fundamental. Parâmetros curriculares nacionais: introdução aos parâmetros curriculares nacionais. Brasília, DF: MEC/SEF, 1997. Disponível em: Acesso em: 02 junho 2018.

Casarin, S. T., Porto, A. R., Gabatz, R. I. B., Bonow, C. A., Ribeiro, J. P., \& Mota, M. S. (2020). Tipos de revisão de literatura: considerações das editoras do Journal of Nursing and Health/Types of literature review: considerations of the editors of the Journal of Nursing and Health. Journal of Nursing and Health, 10(5).

Borçari, A. M. C. G., \& dos Santos, L. G. (2014). A importância da família no processo escolar do aluno. OUTRAS PALAVRAS, 10(2).

Fernandes, A. V. M., \& Paludeto, M. C. (2010). Educação e direitos humanos: desafios para a escola contemporânea. Cadernos Cedes, $30(81), 233-249$.

Freire, P. (1974). Educação como prática da liberdade. Rio de Janeiro: Paz e Terra, 1983. _. Pedagogia do oprimido, 17.

Goergen, Pedro, Educação E Valores No Mundo Contemporâneo. Educação \& Sociedade [en linea] 2005, 26 (Octubre-Sin mes): http://www.redalyc.org/articulo.oa?id=87313714013> ISSN 0101-7330

Galian, C. V. A., \& Carvalho, M. B. D. (2021). Entre reformas curriculares e práticas pedagógicas: Ursula Hoadley e a "pedagogia na pobreza". Educação e Pesquisa, 47 .

Gomes, N. L. (2007). Indagações sobre currículo: diversidade e currículo. Brasília: Ministério da Educação, Secretaria de Educação Básica, 17.

Hayashi, M. C. P. I., \& Gonçalves, T. G. G. L. (2018). Estudo bibliométrico dos balanços da produção científica em Educação Especial na Revista Brasileira de Educação Especial (1999-2017). Revista Brasileira de Educação Especial, 24, 135-152.

Lück, H. (2017). A gestão participativa na escola. Editora Vozes Limitada.

Moreira, A. F. B., \& Candau, V. M. (2007). Indagações sobre currículo: currículo, conhecimento e cultura. Brasília: Ministério da Educação, Secretaria de Educação Básica, 01-48.

Nascimento, C. C. S. D. (2015). Educar para a paz: combatendo a violência na escola.

Oliveira, A. P. F. M. D. (2015). Ensino de Ciências nos anos iniciais do Ensino Fundamental: o que dizem os professores.

Pais, J. M. (2016). Ganchos, tachos e biscates: jovens, trabalho e futuro. XinXii.

Pereira, K. K. (2014). Consequências e implicações do bullying nos envolvidos e no ambiente escolar. Revista Eletrônica de Ciências Jurídicas, 1(2).

Ponce, B. J. (2009). A educação em valores no currículo escolar. Revista e-curriculum, 5(1).

Romeiro, K. L. (2011). A proposta curricular de uma escola rural e sua contribuição para a valorização da vida no campo: estudo de caso na Escola Municipal de Ensino Fundamental Professora Candinha Saraiva, no município de Arroio dos Ratos.

Ropoli, E. A., Mantoan, M. T. E., Santos, M. T. D. C. T. D., \& Machado, R. (2010). A educação especial na perspectiva da inclusão escolar. A escola comum inclusiva.

Salvino, F. P., \& Rocha, V. G. G. (2015). Sentidos de "educação integral” nos meandros do programa Mais Educação. Currículo sem Fronteiras, 15(3), 684714.

Sacadura, C. B. (2018). O currículo como narrativa e a rede dos saberes. Currículo, Formação e Internacionalização: desafios contemporâneos, 61.

Santos B. L., \& Kumada, K. M. O. (2021). Análise metodológica sobre as diferentes configurações da pesquisa bibliográfica. Revista brasileira de iniciação científica, 8, e021029-e021029.

Paula da Costa, V. A. N. D. A. L., \& de Oliveira, S. S. Currículo e projeto pedagógico: análise do perfil de formação de professores em pedagogia na uel. Educação Inclusiva, 95.

Yannoulas, S. C., Assis, S. G., \& Ferreira, K. M. (2012). Educação e pobreza: limiares de um campo em (re) definição. Revista Brasileira de Educação, 17, 329351. 